\title{
Interindividual differences in circadian fatigue patterns of shift workers
}

\author{
O. ÖSTBERG ${ }^{1}$ \\ Logging Research Foundation, Drottninggatan 97, S-11360 Stockholm, Sweden
}

\begin{abstract}
Östberg, O. (1973). BritishJournal of Industrial Medicine, 30, 341-351. Interindividual differences in circadian fatigue patterns of shift workers. Data from 37 computer operators and outputhandlers, working on discontinuous 8-16-24 alternating shifts, were collected in the morning, evening, and night shifts during a one-year period. The study was directed to the interindividual diferences in the workers' circadian patterns of activity, sleep, oral temperature, time estimation, physical fitness, and food intake. By means of a questionnaire on preferences and habits of activity and time of day, three subgroups of five subjects each were selected'morning', 'middle', and 'evening' groups. Significant differences were found between the groups and between the shifts. Most interesting was the significant interaction of group $\times$ shift, on the basis of which it could be concluded that the 'morning' type of subjects had the most pronounced difficulty in adapting to the shift system practised. It is thought that a refinement of the questionnaire used should eventually result in a tool for assessing a person's circadian type and the interaction of type $\times$ shift.
\end{abstract}

It is a generally accepted hypothesis that some individuals are more prone to suffer from shift work than others. Andlauer (1960) and Bruusgaard (1969) estimated that about $20 \%$ of the worker population is unable to adapt to shift work. Sergean (1971), in a review of the practical consequences of shift work, concluded that too little is known (1) about the demands which different types of shift work impose on the workers and (2) about the interindividual differences in the capacity to adapt in various ways to different shift systems and rotas. Wedderburn (1972) advocated that even though interindividual differences too often appear as 'nasty noise' in experimental results, these differences should be studied to understand the influence of circadian rhythms in 'practical life'.

Many authors have explicitly shown that better adaptation to shift work can be obtained by means of a suitable design of the shift system. Colquhoun

${ }^{1}$ Present address: Department of Ergonomics, Loughborough University of Technology, Loughborough, England.
(1971) and Wilkinson and Edwards (1968) found that acceptable adaptation occurred more often in 'stabilized' rather than 'rotating' shifts. Walker (1966) found that very frequent alternation of shifts on continuous work was preferred by the workers to the commonly used one-week spells, due to reduced experience of 'fatigue and monotony'. Bjerner, Holm, and Swensson (1948) showed that workers on continuous alternating shifts starting at the hours 4-12-20 on average obtained more sleep than after a change to 6-14-22. Incidentally, Kleitman (1942) proposed that the 4-12-20 system should be the standard as this conformed to the body temperature cycles of the workers. From the work of Oginski (1966) and Wild and Theis (1967) it can be seen that from both the production and accident reduction points of view the 7-15-23 system is better than the 6-14-22. Finally, it can be concluded from the review by Saito (1969) that it is better to have the shifts in the order night-evening-day, instead of the more common day-evening-night pattern.

The few selection criteria for shift workers found 
today are usually of sociomedical origin. In general, the literature gives no support for abandoning the zero hypothesis that there are no effects of shift work on health per se, but if the shift workers have difficulties in adapting to this style of life, already existing unhealthy conditions might be aggravated. However, if all researchers were as careful as Andersen (1970) the picture would probably change. $\mathrm{He}$ and his associates clearly showed that if one did not stop at registered sicknesses, but went on to look even at 'gastro-intestinal irregularities' and other health defects of limited direct medical significance, one would find negative effects of shift work on health. To reduce this negative effect ThiisEvensen (1958) recommended the rejection of workers living under unsatisfactory housing conditions, as well as those over 50 years of age with no previous experience of shift work. Menzel (1962) added that workers below the age of 25 years might be unsuitable for shift work, especially if they have to provide their own meals. McGirr (1966) listed as the conditions that should in general preclude employees from alternating shift working (1) a need for continuous drug therapy, as for epilepsy and diabetes, (2) serious gastrointestinal diseases, such as ulcer and colitis, (3) heart and circulatory diseases, and (4) marked stress and anxiety syndromes.

Certain personality traits have been proposed as possible selection criteria for shift workers, but these proposals are merely spin-off results of investigations directed to other areas of interest. Aanonsen (1964) found that a high proportion of those workers who had transferred to non-shift work for medical reasons were of the type 'early to bed-early to rise', and suggested that further studies should be done on patterns of sleep and sleep types in order to establish criteria for selection. Similar deductions can be made from a study by Tune (1969a) on non-shift workers, in which it was shown that the older the workers are the more pronounced are the differences between 'extroverts' and 'introverts', the extroverts rising later in the mornings and also getting more sleep on average. In this connection it is important to remember Wilkinson's (1971) statement that loss of sleep may be at least as influential as body rhythms in causing ill effects through abnormal working hours.

Mott, Mann, McLoughlin, and Warwick (1965), whose model for research has stimulated the present study, found that an alternating shift schedule was indeed difficult to adapt to for the younger, better educated worker with small children, while the men who were capable of having additional jobs ('the moonlighters') very seldom complained about the adaptation of their time-oriented body functions, i.e., sleeping, eating, and bowel habits. These moonlighters are perhaps similar to the 'robust individuals' whom Regelsberger (1940) found to be well-adapted shift workers. Häkkinen's (1969) well-adapted group of shift workers showed significantly less psychosomatic tension than his poorly-adapted group.

A few studies have been done on the interindividual differences in the circadian patterns of physiological and psychological variables since Kleitman (1963) drew attention to the existence of 'morning' and 'evening' types of individuals, but none of these studies has been directed to shift work. Pátkai (1971) studied habitual 'morning workers' and 'evening workers' and found so many significant differences in alertness, performance, and adrenal excretion that she suggested that habitual working habits might be an important factor in determining both efficiency of performance and work satisfaction. She also found that the habitual morning workers (in a group of female students) were more introvert than the evening workers, a fact that fits very well with Blake's (1971) summarized findings on 'temperament and time of day', the introvert's body temperature rising a bit earlier in the morning and falling a bit earlier in the evening. Östberg (1973) estimated that the morning types are approximately two hours ahead of the evening types in the circadian rhythms of oral temperature and food intake.

The present study is a continuation of this previous study, in order to test the hypothesis that the questionnaire employed on morning-evening types is sensitive enough to show significant differences even among shift workers. Implicitly it is thus suggested that 'nasty noise' due to interindividual circadian differences is a useful parameter of variation. A new test of physical fitness is also introduced.

\section{Design of investigation}

\section{Background}

The shop steward of the computer department of the Swedish Cooperative Union and Wholesale Society demanded extensive yearly medical examinations for the shift-working members of the local union. During the ensuing negotiations it was agreed that a one-year study, starting in September 1971, should be done on the interindividual differences in the capacity to adapt to the shift system as it was practised. The investigations should centre on the individuals at work rather than at leisure, and should be discontinued when the shift workers did not wish to participate any more. Great efforts, therefore, had to be made to keep the men motivated, and meetings were held regularly to inform them of the progress of the investigation. Neither the participating subjects nor the production of the computer department could be disturbed by the measurements and the data collection, but, on the other hand, the research activities had to be seen to be valid as well as being valid. These restrictions, together with a general lack of resources, had to be considered in designing the investigation.

\section{Subjects and shifts}

When the investigation started there were 36 computer 
operators and 12 output-handlers on shift work. These two groups did not always apply the same shift systems, as some of the operators now and then were sent to training courses and as the production variation influenced the operators more than the output-handlers. In general, the eight-hour spells of the morning, evening, and night shifts started at the hours 08,16 , and 24 respectively, with shift alternations after every weekend cycling in the order night-evening-morning. If a subject was ill or was temporarily working on 'wrong' shift on a scheduled day of measurement, he was captured the next time he worked the same shift. Some worked two shifts only, and some were permanently transferred to other jobs during the year of investigation. As the investigation aimed at studying interindividual differences, these men, and those from whom incomplete data for other reasons had been obtained, had to be excluded from the investigation. Eventually, complete data were collected on 28 operators and 9 output-handlers, who had an average age of 25 and 32 years respectively.

\section{General method \\ It should be pointed out that the different parts of the investigation were spread out over a whole year. The investigation started with every subject answering a questionnaire on 'circadian fatigue pattern', by means of which they could be ranked on a morning-evening continuum. A couple of weeks later they were given sleep charts and asked to record the amount of sleep they had during a four-week period. The next step consisted in measurements of oral temperature at regular intervals during the subjects' working hours. This was done during three days of each type of shift. At the same times a test on time estimation was also run. Some subjects, selected by means of the questionnaire on circadian fatigue pattern, then agreed to make thorough notes on food eaten during three 24-hour periods, one while working morning shift, one on evening shift, and one on night shift. The investi- gation ended with a comparison of these subjects' heart rate and exertion experienced during three different loads on a bicycle ergometer. This test of physical fitness took part early in the morning, late in the evening, and early in the night shifts. The questionnaires were handed out in September 1971 and the last food intake diary was returned in July 1972. It is indeed very time-consuming to study interindividual circadian differences of shift workers.}

\section{Circadian fatigue patterns}

This general expression is in the present context defined by the questionnaire used to rank the subjects on a morning-evening continuum. A detailed description of the questionnaire, the item analysis, and the method of scoring is given in an unpublished thesis in Swedish by Öquist (1970). When employed here, the questionnaire was slightly shortened and the method of scoring simplified.

The questionnaire contained 14 items equally distributed between morningness and eveningness. The items dealt with preferences and habits concerning activity and time of day 'on days when you are not too restricted by schedules of society, family, and work'. Typical morningness and eveningness items were:
-Do you experience difficulties in getting out of bed when you wake up in the morning? (a) Very often (b) Sometimes (c) Seldom (d) Very seldom -If you were free to choose, at what time would you go to bed at night? (a) After 0100 (b) Between $2330-0100$ (c) Between 2200-2330 (d) Before 2200 Scores were calculated by means of the method of complementary proportions within the population. Given a specific item where, in order, ' $a$ ', 'b', 'c', 'd' indicated 'extreme morningness', 'morningness', 'eveningness', 'extreme eveningness', if the proportion of the subjects who gave these answers were ' 0.1 ', ' 0.2 ', ' 0.5 ', ' 0.2 ' their scores would be ' +0.9 ', ' +0.8 ', ' -0.5 ', ' 0.8 ' respectively. The total score for a subject was obtained by adding the item scores.

\section{Sleep}

The subjects' sleep and wakefulness patterns were registered for a period of four consecutive weeks. The registration period covered one week of each type of shift. The subjects were given two sleep charts, each of which covered two weeks, and asked to mark the obtained amount of sleep to the nearest half-hour. The charts were Swedish equivalents to the charts described by Tune (1968) and had a remarks column for illness, medication, and unusual occurrences upsetting the daily routines.

\section{Oral temperature}

Oral temperature measurements were done during the first, third, and fourth day of work on each shift. No measurements were taken in the subjects' leisure hours. Each shift was divided into five intervals and the workers took one temperature reading per interval. The thermometer allowed registration in tenths of centigrades and had to be placed under the tongue for three minutes, but this was hard to check as the subjects often had to carry on with their work at the same time. Measurements were never done immediately after food intake or smoking.

\section{Time estimation}

Parallel to the measurements of oral temperature, and at the same times, measurements were also done on the 'speed of the subjects' internal clocks'. The subjects were individually asked to estimate the length of a time period of 10 seconds by means of silent counting, and this was registered on an electronic counter operated by 'start' and 'stop' pushbuttons. No knowledge of the results was given. The hypothesis for this test was that the ' 10 subjective seconds' should become objectively longer during the night because of slower speed of the subject's 'internal counting device'. Blake (1967) found no significant time of day effects in a similar experiment, but, on the other hand, it was shown by Pfaff (1968) and Thor (1962) that the interindividual differences are very large sources of variation in experiments of this type.

\section{Physical fitness}

This new test is based on the comparison between the subject's actual heart rate and the subjective workload. Voigt, Engel, and Klein (1968) showed that there is a clear circadian rhythm of heart rate for fixed loads in bicycle ergometer tests. Borg (1971) designed a scale for subjective ratings of workloads, and found that the 
regression line of the experienced workload on the heart rate was different for different age groups of subjects. Based on this knowledge, an experimental procedure was then designed to test the hypothesis that as assessed by the test of physical fitness, a morning type of subject is 'older' in the evenings than in the mornings and vice versa for an evening type of subject. The tests were run at the workplace during the third day's work on each shift at the hours 0925,2225 , and 0245 respectively.

In a pretest, the bicycle workloads were individually chosen to give a day-time heart rate of about 140; one load should give a somewhat lower and another a somewhat higher heart rate. At every test session the subjects always had the same loads. Starting with the smaller load, the subject's heart rate was taken as the mean value of the fourth, fifth, and sixth minutes of work at each load. During the fourth minute the subjects were shown the Borg scale and asked to assess the workload in terms of experienced exertion. The experimental setup and the instructions to the subjects were designed in such a way that the subjects were always unaware of the actual load.

\section{Food intake}

In the food intake diaries the subjects were asked to make thorough notes on everything eaten during a 'normal' 24-hour period in the middle of each type of shift. Not all subjects agreed to 'waste their time' on these diaries, but eventually the five most extreme morning, middle, and evening types, as well as some reserves, took part in the investigation.

\section{Results}

\section{Circadian fatigue patterns}

Mostly due to the cumbersome recording of food intake it was decided not to use each subject's score on the morning-evening continuum, but rather to select three groups of five subjects each. These groups will further on be dealt with under the subtitle 'interindividual differences'. Depending on what part of the morning-evening continuum the groups belonged to, they will be called morning, middle or evening group. Due to incomplete data some reserves had to be taken into the groups during the food intake part of the investigation.
Sleep

As an overall description of the sleep of the 37 shiftworking subjects, their average amount of sleep throughout the shift cycle is given in Table 1 . This clearly gives the same picture of the sleep of shift workers as the study by Tune (1969b) and Lille (1967).

\section{Interindividual differences}

The questionnaire on circadian fatigue patterns was designed to differentiate between morning and evening types of subjects according to their habits and preferences concerning time of day during days 'when you are not too restricted by schedules of society, family, and work'. To test whether the five most extreme morning types and the five most extreme evening types had slept as could have been predicted from the questionnaire, their cumulative distributions of hours of weekend sleep are pictured in Figure 1.

By means of the one-tailed Kolmogorov-Smirnov test the difference between the two distributions in Fig. 1 was found to be significant at the 0.01 level. The next step was to test the hypothesis that the sleep patterns were also different during weekdays, and that there were large enough differences to indicate the degree of adaptation to different shifts. In this case it was not possible to employ a directed hypothesis as the only belief was that the middle group should always come between the morning and evening groups. In order to perform an analysis of variance test on the sleep data, each subject's amount of sleep obtained during work on the different shifts is calculated, and the results are presented in Table 2.

The entries in Table 2 give, for each group and shift, the total amount of sleep during four days' work (Monday evening to Friday evening). The amount of sleep is expressed as a percentage of the total amount of sleep obtained during the 21 days in succession that covered all three shifts, and this was first calculated separately for each subject and then averaged into the table. It can be seen that the

TABLE 1

Average Amount of Sleep (Hours) during a Typical Weekday and Weekend Day, Compiled from 37 SubJects' Sleep Charts Covering Four Consecutive Weeks

\begin{tabular}{l|ccc}
\hline Shift & $\begin{array}{c}\text { Weekday sleep during } \\
\text { on-going work in shift }\end{array}$ & $\begin{array}{c}\text { Weekend sleep after } \\
\text { having worked one week } \\
\text { in shift }\end{array}$ & $\begin{array}{c}\text { Total average sleep } \\
\text { during fve week days and } \\
\text { following weekend }\end{array}$ \\
\hline Morning & $7 \cdot 1$ & $8 \cdot 4$ & $7 \cdot 5$ \\
Evening & $7 \cdot 6$ & $7 \cdot 8$ & $7 \cdot 7$ \\
Night & $6 \cdot 1$ & $8 \cdot 0$ & $6 \cdot 6$ \\
\hline Mean & 6.9 & $8 \cdot 1$ & $7 \cdot 3$ \\
\hline
\end{tabular}




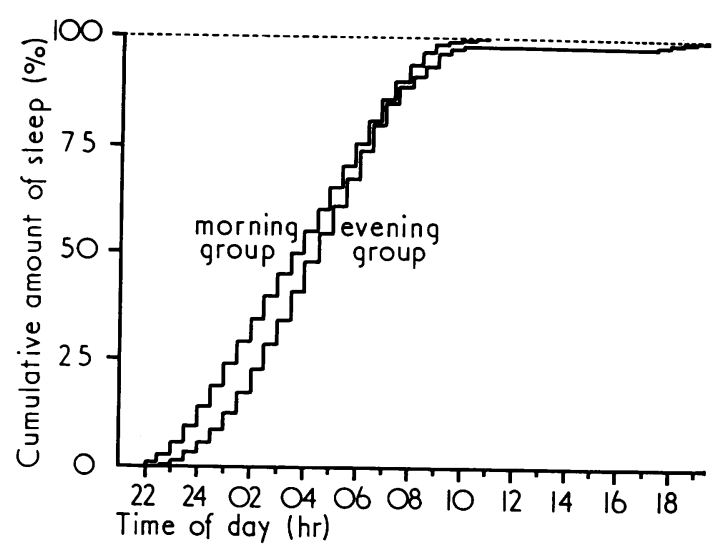

FIG. 1. Cumulative amount of sleep of the morning and evening groups during three weekends (Saturday at 2200 to Sunday at 2200 hours). $100 \%$ represents the total amount of sleep during the three weekends. The separation between the distributions is significant $(0.01$, one-tailed Kolmogorov-Smirnov test) in the predicted direction.

different groups of subjects exhibit different patterns of sleep throughout the shift cycle. It appears that the morning types experienced most interference of work on sleep during the night shift. As expected, the morning types slept best on the morning shift week and the evening types slept best on the evening shift week. One can have confidence in this extraction of information from the table, as the F-test showed that the levels of significance of the sources of variance were: group (0.05), shift (0.001), and group $X$ shift $(0 \cdot 07)$. By group $X$ shift is meant the interaction between the groups (morning, middle, evening) and the shifts (morning, evening, night), and if the interaction is significant the conclusion must be that the different groups were affected in different ways by the shift cycle to which they were exposed.
It can also be concluded from Table 2 that the middle group subjects were affected in an intermediate way, intermediate to the morning and evening groups.

\section{Oral temperature}

No measurements of oral temperature were done outside the workplace and hence no real circadian rhythm of oral temperature can be calculated, but it is still possible to obtain circadian information from the data. As a start, all oral temperature data are averaged into the graph shown in Figure 2.

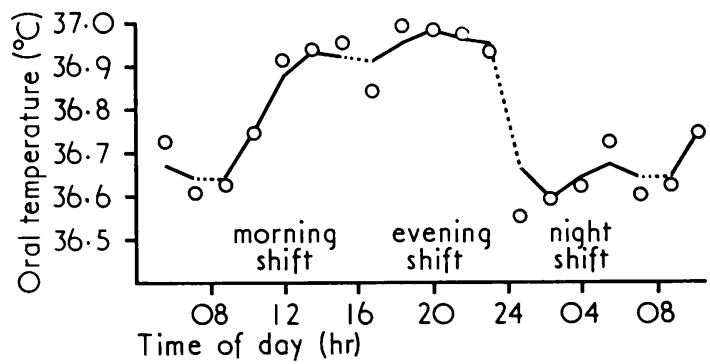

FIG. 2. The mean of 37 subjects' oral temperatures during their first, third, and fourth days of work on the different shifts. The graph (weighted three-point running averages) is a composite of the measurements of the three disjoint shifts and does not show the subjects' circadian rhythm but shows rather their on-work oral temperatures. The grand mean is $36.8^{\circ} \mathrm{C}$.

Figure 2 does not therefore show the circadian rhythm of the studied group of subjects but it shows the group's on-the-work oral temperature. The data cover five equally spaced measurements on the first, third, and fourth days of work on each shift, and if one believes in the existence of a strong correlation

TABLE 2

Amount of Sleep Obtained during Four Days' (Monday Evening to Friday Evening) Work

\begin{tabular}{|c|c|c|c|c|c|c|}
\hline \multirow{2}{*}{\multicolumn{3}{|c|}{ Group }} & \multicolumn{3}{|c|}{ Shift } & \multirow{2}{*}{ Mean } \\
\hline & & & \multirow{2}{*}{$\begin{array}{c}\text { Morning } \\
18 \cdot 2 \\
17 \cdot 9 \\
17 \cdot 7\end{array}$} & \multirow{2}{*}{$\begin{array}{c}\text { Evening } \\
18 \cdot 5 \\
20 \cdot 4 \\
21 \cdot 1\end{array}$} & \multirow{2}{*}{$\begin{array}{c}\text { Night } \\
16 \cdot 5 \\
17 \cdot 4 \\
17 \cdot 6\end{array}$} & \\
\hline $\begin{array}{l}\text { Morning types } \\
\text { Middle types } \\
\text { Evening types }\end{array}$ & $\begin{array}{l}\cdots \\
\cdots \\
\cdots\end{array}$ & $\begin{array}{l}\cdots \\
\cdots \\
\cdots\end{array}$ & & & & $\begin{array}{l}17 \cdot 7 \\
18 \cdot 6 \\
18 \cdot 8\end{array}$ \\
\hline Mean & .. & $\ldots$ & $17 \cdot 9$ & $20 \cdot 0$ & $17 \cdot 2$ & 18.4 \\
\hline
\end{tabular}

For each group/shift combination the sleep is given as a percentage of all sleep obtained by the group during the 21 consecutive days that covered one shift cycle. Significant sources of variance (F-test) are group $(0.05)$, shift $(0.001)$, and group $\times$ shift interaction (0.07). 
TABLE 3

Oral Temperature of Different Group/Shift Combinations

\begin{tabular}{|c|c|c|c|c|c|c|}
\hline \multirow{2}{*}{\multicolumn{3}{|c|}{ Group }} & \multicolumn{3}{|c|}{ Shift } & \multirow{2}{*}{ Mean } \\
\hline & & & Morning & Evening & Night & \\
\hline $\begin{array}{l}\text { Morning types } \\
\text { Middle types } \\
\text { Evening types }\end{array}$ & $\begin{array}{l}\cdots \\
\cdots \\
\cdots\end{array}$ & $\begin{array}{l}. \\
\cdots \\
\cdots\end{array}$ & $\begin{array}{l}36 \cdot 79 \\
36 \cdot 80 \\
36 \cdot 99\end{array}$ & $\begin{array}{l}36 \cdot 90 \\
36 \cdot 86 \\
37 \cdot 16\end{array}$ & $\begin{array}{l}36 \cdot 67 \\
36 \cdot 58 \\
36 \cdot 91\end{array}$ & $\begin{array}{l}36 \cdot 79 \\
36 \cdot 75 \\
37 \cdot 02\end{array}$ \\
\hline Mean & $\cdots$ & .. & $36 \cdot 86$ & 36.97 & $36 \cdot 72$ & $36 \cdot 85$ \\
\hline
\end{tabular}

Each entry gives the mean of all measurements during the first, third, and fourth days of work. Significant sources of variance (F-test) are group $(0.025)$ and shift $(0.05)$.

between body temperature and performance efficiency one could say that the graph shows the "circadian rhythm of efficiency of the computer department'. Unfortunately, no efficiency measures were to be found for the subjects or the department.

\section{Interindividual differences}

The on-work oral temperatures of the morning, middle, and evening groups during the morning, evening, and night shifts are summarized in Table 3.

An analysis of variance of the data underlying Table 3 shows that group and shift are significant sources of variance $(0.025$ and 0.05 , F-test $)$ whereas the interaction group $\times$ shift is a non-significant source. However, the negative finding concerning the interaction does not mean that there was no interaction, and another type of analysis might reveal the looked for significance. If the different groups' maxima of oral temperature are not well enough separated in the time base to be detected by the analysis of variance, additional information could be obtained by means of Fourier analyses of each subject's temperature data. Figure 3 summarizes such an attempt.

Each curve in Fig. 3 is based on the 24-hour Fourier components of each of the group members. It can be seen that the averaged levels (in ${ }^{\circ} \mathrm{C}$ ), amplitudes (in ${ }^{\circ} \mathrm{C}$ ), and maxima (at $\mathrm{hr}$ ) were $36 \cdot 8 / 0 \cdot 24 / 1610,36 \cdot 8 / 0 \cdot 25 / 1636$, and $37 \cdot 0 / 0 \cdot 39 / 1834$ for the morning, middle, and evening groups. As before, the differences between the overall levels $\left(36 \cdot 8-37 \cdot 0^{\circ} \mathrm{C}\right)$ were significant according to the twotailed $t$ test, but the only other difference worth mentioning is the time separation of 2.4 hours between the maxima of the morning and evening groups $(0 \cdot 2$, one-tailed $t$ test). A Fourier extraction of the eight-hour components of the oral temperatures gave no further information.

\section{Time estimation}

The time estimations took place at the same times as

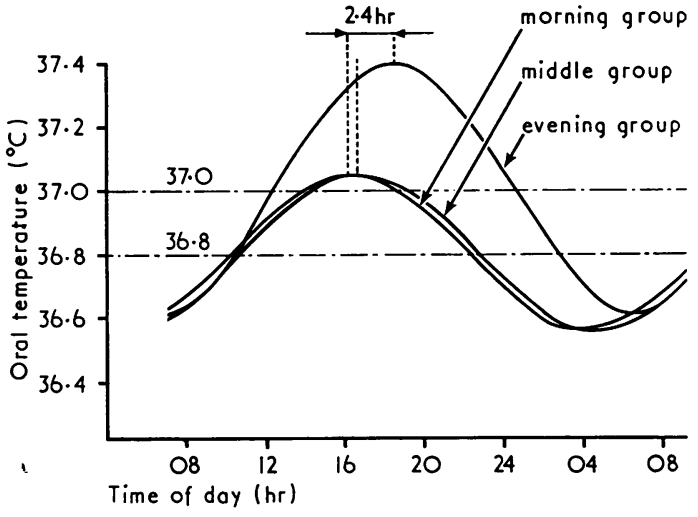

FIG. 3. The 24-hours sinusoidal components of the oral temperature of the morning, middle, and evening groups. Each curve is drawn on the basis of the average Fourier parameters of the individual subjects. The time separation of 2.4 hours between the morning and evening groups has a level of significance of $0 \cdot 20$ (one-tailed $t$ test).

the measurements of oral temperature and the time estimation data can in principle be presented in the same form, as has been done for the temperature data in Figure 2. This is also done in Fig. 4, but the within-shift variation is too large to allow the drawing of a circadian on-work graph similar to that for oral temperature.

The grand mean of the time estimations ' 10 seconds' was $\mathbf{9 . 9 3}$ seconds and, as shown in Fig. 4, the general trend was that the estimated times became objectively longer at the end of each shift. This within-shift trend was expected due to the hypothesis that the more fatigued the subjects were, the slower would their 'internal counting device' run. However, the interest should be focused rather on the between-shifts trend, and this is indicated in the 


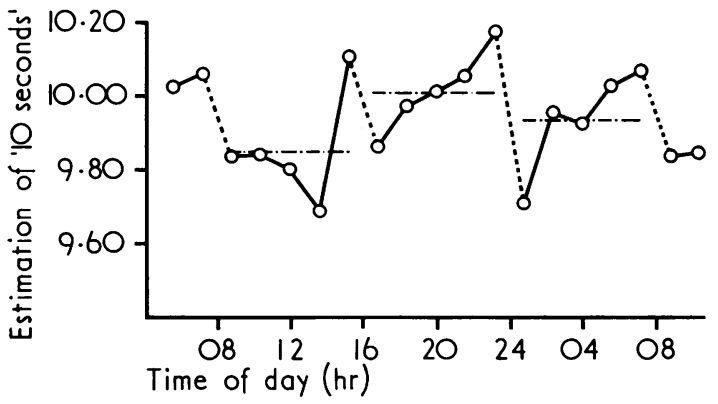

FIG. 4. The mean of 37 subjects' estimations of 10 seconds (by means of the method of production) during their first, third, and fourth days of work in the different shifts. The grand mean is 9.93 seconds.

figure by the differences between the shifts' mean '10 seconds'.

Interindividual differences

Unfortunately, the time estimations started without any training to 'count to ten' and it was found too late that one of the morning group subjects constantly produced estimates of about 4.5 seconds. As the groups had just five members this type of bias in one single subject will influence the group means, and especially it meant here that the morning group had a too low mean (Table 4).

The F-test shows that the sources of variance of the Table 4 data are group (0.001), shift $(0 \cdot 2)$, and group $\times$ shift $(0.002)$, where, as explained above, the importance of the significant variation due to group is limited. Due to the hypothesis of this experiment the night shift estimations should be longer than the day shift estimations and this tendency was also found, but the most reliable and interesting finding was the significant interaction of group $\times$ shift. This interaction can be read out from the table: the morning group is most affected by the night shift, the evening group is most affected by the morning shift, and the middle group is affected in an intermediate way.

\section{Physical fitness}

The scale employed for assessment of the exertion experienced had been designed to give a regression line equal to the line marked 'Borg (1971)' in Figure 5. Borg's experiments were all performed in day-time, and a minor deviation from these results could naturally arise when night-time experiments are included as well. But when all data of the morning, evening, and night tests were put together, the resulting regression line (Fig. 5) was seen to deviate only slightly from the day-time expectation.

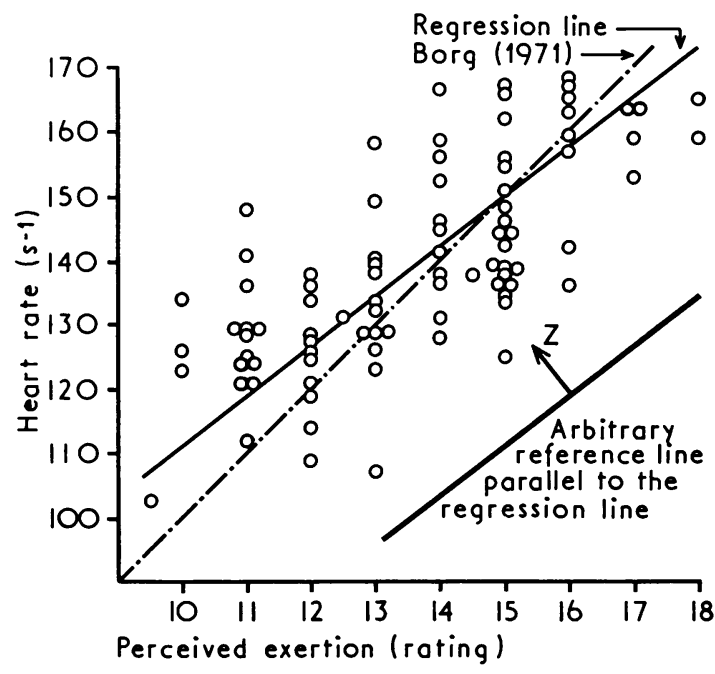

FIG. 5. Heart rate and perceived exertion during work on bicycle ergometer. Each point represents a subject classed in either morning, middle or evening group, five subjects per group, two individually chosen loads per subject, and the same loads during each shift at 0925 , 2225 , and 0245 hours respectively. The tests were run during the third day's work in the shifts.

TABLE 4

Average Time Estimations for Different Group/Shift Combinations

\begin{tabular}{|c|c|c|c|c|c|c|}
\hline \multirow{2}{*}{\multicolumn{3}{|c|}{ Group }} & \multicolumn{3}{|c|}{ Shift } & \multirow{2}{*}{ Mean } \\
\hline & & & Morning & Evening & Night & \\
\hline $\begin{array}{l}\text { Morning types } \\
\text { Middle types } \\
\text { Evening types }\end{array}$ & $\begin{array}{l}\ldots \\
\cdots \\
\cdots\end{array}$ & $\begin{array}{l}\ldots \\
\cdots \\
\cdots\end{array}$ & $\begin{array}{r}8 \cdot 85 \\
10 \cdot 18 \\
10 \cdot 46\end{array}$ & $\begin{array}{r}8 \cdot 85 \\
10 \cdot 50 \\
9 \cdot 76\end{array}$ & $\begin{array}{r}9 \cdot 34 \\
10 \cdot 35 \\
10 \cdot 05\end{array}$ & $\begin{array}{r}9 \cdot 01 \\
10 \cdot 34 \\
10 \cdot 09\end{array}$ \\
\hline Mean & $\cdots$ & $\ldots$ & $9 \cdot 83$ & $9 \cdot 70$ & $9 \cdot 91$ & $9 \cdot 81$ \\
\hline
\end{tabular}

The sources of variation (F-test) are group (0.001), shift $(0.20)$, and group $\times$ shift $(0.002)$. 
TABLE 5

Averaged Scores of Physical fitness (As Defined by Z in Fig. 5) for Different Group/Shift Combinations

\begin{tabular}{|c|c|c|c|c|c|c|}
\hline \multirow{2}{*}{\multicolumn{2}{|c|}{ Group }} & & \multicolumn{3}{|c|}{ Shift } & \multirow{2}{*}{ Mean } \\
\hline & & & Morning & Evening & Night & \\
\hline $\begin{array}{l}\text { Morning types } \\
\text { Middle types } \\
\text { Evening types }\end{array}$ & $\begin{array}{l}\cdots \\
\cdots \\
\cdots\end{array}$ & $\begin{array}{l}\cdots \\
\cdots \\
\ldots\end{array}$ & $\begin{array}{l}37 \cdot 9 \\
34 \cdot 7 \\
29 \cdot 8\end{array}$ & $\begin{array}{l}36 \cdot 4 \\
33 \cdot 0 \\
34 \cdot 5\end{array}$ & $\begin{array}{l}20 \cdot 8 \\
25 \cdot 8 \\
27 \cdot 7\end{array}$ & $\begin{array}{l}31 \cdot 7 \\
31 \cdot 2 \\
30 \cdot 7\end{array}$ \\
\hline Mean & $\cdots$ & $\ldots$ & $34 \cdot 1$ & $34 \cdot 6$ & $24 \cdot 8$ & $31 \cdot 2$ \\
\hline
\end{tabular}

The higher the score, the more fit. Significant sources of variance (F-test) are shift $(0.001)$ and group $\times$ shift $(0.05)$. No age differences between the groups.

\section{Interindividual differences}

In Borg's experiments, the regression lines of the older age groups run parallel to, but below, the regression lines of the younger age groups. If a shift worker has difficulties in adapting to the night shift he can be thought of as being 'older' during the night shift, and the further below the day-time regression line the night-time regression line is, the 'older' and less fit he is. Thus, the parallel displacements can be used as measures of physical fitness. The distance $Z$ between the subject (given by the subject's heart rate and corresponding exertion experienced) and the reference line (arbitrary below, but parallel to, the regression line) of Fig. 5 can thus be used in expressing the subject's physical fitness: the larger the $\mathrm{Z}$-value, the greater the fitness. Of course, the $Z$-value in isolation says nothing about the fitness; one should rather compare the intra-subject differences in Z-values obtained during different conditions. Table 5 gives the $\mathrm{Z}$-values of the three groups at the three times of measurements.

An analysis of variance on the data summarized in Table 5 very nicely confirms the hypothesis that the subjects were less fit during the night shift, the F-test level of significance being $0 \cdot 001$. But the most interesting result is that the interaction group $\times$ shift was also a significant $(0.05)$ source of variance, especially in the light of the non-significant variance due to group. Concluding the findings, it can be said that (1) there were no differences in physical fitness between the groups, (2) the lowest scores of physical fitness were obtained during the night shift, and (3) the morning group subjects were least fit during the beginning of the night shift, the evening group subjects were least fit during the beginning of the morning shift, and the middle group subjects were affected in an intermediate way.

\section{Food intake}

All food was analysed for its content of energy and other nutritional factors. Averages were then calculated for each of the following subgroups: morning, middle, and evening types; morning, evening, and night shifts; all subjects together. All these averages showed that the typical shift working subject had a well-balanced food intake according to Recommended Dietary Allowances (1968). A more thorough analysis was done on the amount and time patterns of the energy contert in kilo joules ( $\mathrm{kJ}$ ) of the food intakes. The overall dead-point of food intake was

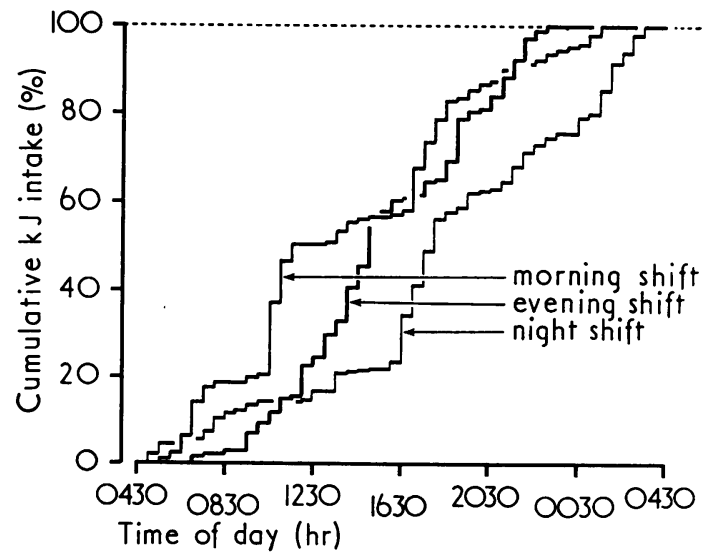

FIG. 6. Cumulative food intake (kJ) during a 24-hour period in the middle of a week on morning, evening, and night shift respectively. The curves are obtained by adding the individually normalized curves of the subjects in the morning, middle, and evening groups. Each subject's kJ-count starts at the hour 0430 , which was the overall dead-point of food intake. 
found to be at the hour 0430 in the middle of the night, and this was taken as the starting point of the cumulative kJ-count shown in Figure 6.

In calculating the circadian food intake distribution shown in Fig. 6, a normalization was first carried out. The total food intake of each subject's 24-hour registration (one registration per shift type) was set to $100 \%$, then every half-hour's food intake was expressed accordingly, and finally all subjects' normalized cumulative food intakes were added to the total food intake distributions for the morning, evening, and night shifts. It is seen from Fig. 6 that these distributions are quite well separated, with approximately 4 hours difference between the principal food intake periods of successive shifts (at hours 1100, 1300, and 1700). The two-tailed Kolmogorov-Smirnov test shows that the differences are all well beyond the 0.001 level of significance.

\section{Interindividual differences}

It has already been shown that the time separation in principal food intake was 4 hours between the 8 hours-separated shifts. It was thought that the interindividual differences in the degree of adaptation would be manifested in different time patterns of food intake, and cumulated distributions of the type shown in Fig. 6 were also calculated for each shift/group combination. To get at the intragroup intershift differences, the two-tailed KolmogorovSmirnov test was employed in the comparisons between the distributions, and the results are shown in Table 6.

Table 6 tells nothing about how many hours' differences there are between the distributions; it merely tells the significance levels of the overall differences between the time patterns. For example, the entry ' 0.001 ' for the evening types in the morningevening comparison means that the evening types ate significantly differently during the morning and evening shifts, and ' $0 \cdot 1$ ' for the morning types in the evening-night comparison means that the morning types hardly changed their eating habits during the evening and night shifts. The amount of food intake (kJ) was also looked at, and this was done by means of the F-test, but the only source of variance of any importance was the interaction group $\times$ shift. In order that the nature of this interaction might show up more clearly, the kJ-intakes are expressed in percentage deviation from the group means. The results (Table 7) seem to indicate that

\section{TABLE 6}

LeVELS OF Significance (Two-TAILED Kolmogorov-SMiRnov TeST) FOR INTRAGROUP INTERSHIFT Differences between Cumulative Food Intake Distributions of Different Group/Shift Combinations

\begin{tabular}{|c|c|c|c|c|}
\hline \multirow{2}{*}{\multicolumn{2}{|c|}{ Group }} & \multicolumn{3}{|c|}{ Comparison between shifts } \\
\hline & & Morning/evening & Morning/night & Evening/night \\
\hline $\begin{array}{l}\text { Morning types } \\
\text { Middle types } \\
\text { Evening types }\end{array}$ & $\begin{array}{ll}\cdots & . \\
\cdots & . \\
. & .\end{array}$ & $\begin{array}{l}0.05 \\
0.05 \\
0.001\end{array}$ & $\begin{array}{l}0.01 \\
0.001 \\
0.001\end{array}$ & $\begin{array}{l}0.1 \\
0.001 \\
0.001\end{array}$ \\
\hline All together & $\ldots \quad \ldots$ & 0.001 & 0.001 & 0.001 \\
\hline
\end{tabular}

The statistical test used can detect any difference whatsoever, but there were only time displacements detectable between the actual distributions (see Fig. 6).

TABLE 7

Percentage Differences of Food Intake (kj) Between Shifts

\begin{tabular}{|c|c|c|c|c|c|c|}
\hline \multirow{2}{*}{\multicolumn{4}{|c|}{ Group (average $k J$-intake) }} & \multicolumn{3}{|c|}{ Shift } \\
\hline & & & & Morning & Evening & Night \\
\hline $\begin{array}{l}\text { Morning types }(100 \%=11650) \\
\text { Middle types }(100 \%=10280) \\
\text { Evening types }(100 \%=11000)\end{array}$ & $\begin{array}{l}\cdots \\
\cdots\end{array}$ & $\begin{array}{l}\cdots \\
\ldots\end{array}$ & $\begin{array}{l}\cdots \\
\ldots\end{array}$ & $\begin{array}{l}+12.2 \\
-5.2 \\
-8.5\end{array}$ & $\begin{array}{l}-7 \cdot 2 \\
+4 \cdot 2 \\
-7 \cdot 3\end{array}$ & $\begin{array}{l}-5.0 \\
+1.0 \\
+15.8\end{array}$ \\
\hline$(100 \%=11090)$ & . & .. & . & -1.4 & $-3 \cdot 7$ & $+4 \cdot 0$ \\
\hline
\end{tabular}

Each group is treated separately. The source that contributed most to the total variance was the interaction group $\times$ shift (0.25, F-test). 
the morning group subject ate 'best' during the morning shift, the middle group during the evening shift, and the evening group during the night shift.

\section{Discussion and conclusions}

The results give the general impression that the subjects were not well enough adapted to the night shift. This general impression can be approximately quantified by the following method. Suppose that equal weights are given to all measures employed (sleep, oral temperature, time estimation, physical fitness, and food intake), the results (in Tables 2, 3, 4,5 , and 7 respectively) could be combined by simply adding the 'adaptation scores' calculated separately for each table of results. The concept 'adaptation score' is most conveniently explained by referring to Table 2, where the best and the worst adaptations are judged to have occurred for the evening types while working the evening shift, and the morning types while working the night shift; the 'adaptatation scores' being ' 1 ' and ' 9 ' respectively. When all the within-table scores are combined, the results become as in Table 8 .

Table 8 also provides an example of how the 'adaptation scores' were calculated: the scores that could be assigned to the group/shift combinations within the table are given in brackets. The total score of 99 for the night shift supports the impression that the night shift was the most difficult to adapt to, the total score of 67 for the evening group indicates that the evening types had the least overall difficulty in adapting to the schedule of shift work as it was, and the total score of 39 for the morning types in the night shift column that the morning types had the most pronounced difficulty in adapting to the night shift. These conclusions are confirmed, as the Kruskal-Wallis one-way analysis of variance used on the within brackets numbers gives a significance level of $0 \cdot 02$.

The total scores of the groups, shown in the right- hand column of Table 8, tell that the evening group had the least overall difficulty in adapting to the shift schedule, but that there were no differences between the morning and middle groups. However, the calculation of 'adaptation scores' was based only on the ordered values of the separate tables, and no use was made of the numerical differences between these values. If then (as a second approximation) Table 8 is 'corrected' for these numerical differences (e.g., the very low score of physical fitness for the morning group during the night shift), it appears that the morning group subjects had the most overall difficulty in adapting to the schedule of shift work used.

It has been shown that the evening types of subjects had the least difficulty in adapting to the shift schedule, that the morning types had the most difficulty, and that the middle types adapted in an intermediate way. The very same conclusions can post hoc be drawn from Table 6, which also offers a hypothetical explanation for the differences and suggests directions for future research. From Table 6 it can be seen that the evening types had markedly changed time patterns of food intake during the different shifts, whereas the morning types had less marked changes and especially they seem to eat in the same way during the evening and night shifts. But did the morning types have difficulties in adapting to the shift schedule because they did not change their eating habits, or was it the other way? This cannot be analysed further from the present data. More research is needed to test the hypothesis that the morning types have a more autonomous circadian rhythm than the evening types.

All measures used in the investigation seem to have fulfilled the purpose of delineating the interindividual difference in adaptation to the shifts, and it is remarkable that the crude questionnaire was of such power that the interactions group $\times$ shift became significant in spite of the very small samples $(\mathrm{N}=5)$ selected from the very small population

TABLE 8

Total 'Adaptation Scores' for Different Group/Shift Combinations

\begin{tabular}{|c|c|c|c|c|c|c|}
\hline \multirow{2}{*}{\multicolumn{3}{|c|}{ Group }} & \multicolumn{3}{|c|}{ Shift } & \multirow{2}{*}{ Total } \\
\hline & & & Morning & Evening & Night & \\
\hline $\begin{array}{l}\text { Morning types } \\
\text { Middle types } \\
\text { Evening types }\end{array}$ & $\begin{array}{l}\cdots \\
\ldots \\
\ldots\end{array}$ & $\begin{array}{l}. \\
\cdots \\
\ldots\end{array}$ & $\begin{array}{l}21(3 \cdot 5) \\
24(5) \\
26(6 \cdot 5)\end{array}$ & $\begin{array}{l}19(2) \\
21(3 \cdot 5) \\
15(1)\end{array}$ & $\begin{array}{l}39(9) \\
34(8) \\
26(6 \cdot 5)\end{array}$ & $\begin{array}{l}79 \\
79 \\
67\end{array}$ \\
\hline Total & & . & 71 & 55 & 99 & 225 \\
\hline
\end{tabular}

The lower the score, the better the adaptation. The total scores are obtained by adding the scores obtained with in each of Tables $2,3,4,5$, and 7 (the method of scoring is exemplified by the scoring within this table, as shown by the scores given in parentheses). A one-way analysis of variance shows the total score pattern is of significance (0.02, Kruskal-Wallis). 
$(\mathrm{N}=37)$. The crucial point then is the questionnaire itself. More work is needed before the questionnaire can be used as a routine in shift work investigations. Another crucial point is how the interindividual circadian differences should be analysed and what sort of statistical tests to employ. Various techniques have been tried in the present study, and the reader might have difficulty in seeing the shift working computer staff who were the subjects behind all the levels of significance. Certainly, much effort was put into the problems of detecting the interindividual differences and in extracting the most relevant data for the tables, but the ever present purpose of the investigation was still to do research on behalf of the shift workers rather than merely on the shift workers.

I should like to thank the computer staff who served as subjects. Thanks are also due to Adam Kamien, Andrew Nicholl, and Henning Wittmeyer for their help during the data collection for, and the preparation of, this paper.

This study has been supported partly by the Swedish Co-operative Union and Wholesale Society, where I worked as ergonomist when the study was initiated.

\section{References}

Aanonsen, A. (1964). Shift Work and Health. Universitetsforlaget, Oslo.

Andersen, J. E. (1970). Three-shift Work. A Socio-medical Survey. Teknisk Forlag, Copenhagen.

Andlauer, P. (1960). The effect of shift-working on the worker's health. OEEC Trade Union Information, 29, 3-9.

Bjerner, B., Holm, Å., and Swensson, Å. (1948). Om natt och skiftarbete. Statens Offentliga Utredningar, 51, 87-160.

Blake, M. J. F. (1967). Time of day effects on performance in a range of tasks. Psychonomic Science, 9, 349-350. (1971). Temperament and time of day. In Biological Rhythms and Human Performance, edited by W. P. Colquhoun, pp. 109-148. Academic Press, London/ New York.

Borg, G. (1971). Psychological and physiological studies of physical work. In Measurement of Man at Work, edited by W. T. Singleton, J. G. Fox, and D. W. Whitfield, pp. 121-128. Taylor and Francis, London.

Bruusgaard, A. (1969). Shift work as an occupational health problem. Studia Laboris et Salutis, 4, 9-14.

Colquhoun, W. P. (1971). Circadian variations in mental efficiency. In Biological Rhythms and Human Performance, edited by W. P. Colquhoun, pp. 39-107. Academic Press, London/New York.

Häkkinen, S. (1969). Adaptability to shift work. Studia Laboris et Salutis, 4, 68-80.

Kleitman, N. (1942). Sunset, night and dawn shifts for 'round-the-clock' production. Steel, 2, 72.

(1963). Sleep and Wakefulness, 2nd ed. University of Chicago Press, Chicago.

Lille, F. (1967). Le sommeil de jour d'un groupe de travailleurs de nuit. Le Travail Humain, 30, 85-97.

McGirr, P. O. M. (1966). Health considerations: shift work and health. Proceedings of the Production Engineering
Research Association. Melton Mowbray.

Menzel, W. (1962). Menschliche Tag-Nacht-Rhythmik und Schichtarbeit. Schwabe, Basel/Stuttgart.

Mott, P. E., Mann, F. C. McLoughlin, Q., and Warwick, D. P. (1965). Shift Work: the Social, Psychological and Physical Consequences. University of Michigan Press, Ann Arbor.

Oginski, A. (1966). Comparative research into the work on three shifts: morning, afternoon and night. Proceedings of the 15th International Congress on Occupational Health, Vienna. 1966. vol. 6, pp. 384-385.

Öquist, O. (1970). Kartläggning av Individuella dygnsrytmer. University of Gothenburg, Gothenburg. Unpublished thesis at the Department of Psychology.

Östberg, O. (1973). Circadian rhythms of food intake and oral temperature in 'morning' and 'evening' groups of individuals. Ergonomics, 16, 203-209.

Pátkai, P. (1971). The diurnal rhythm of adrenal secretion in subjects with different working habits. Acta Physiologica Scandinavica, 81, 30-34.

Pfaff, D. (1968). Effects of temperature and time of day on time judgements. Journal of Experimental Psychology, 76, 419-422.

Recommended Dietary Allowances (1968). 7th revised edition. The Food and Nutritional Board of the National Academy of Science, Washington.

Regelsberger, H. (1940). Über die cerebrale Beeinflussung der vegetativen Nahrungsrhythmik. Zeitschrift für die gesamte Neurologie und Psychiatrie, 169, 532-542.

Saito, H. (1969). Shift work. In Occupational Health in Japan, pp. 152-161. The Organizing Committee of the 16th International Congress on Occupational Health, Tokyo.

Sergean, R. (1971). Managing Shift Work. Gower Press, London.

Thiis-Evensen, E. (1958). Shift work and health. Industrial Medicine and Surgery, 27, 493-497.

Thor, D. H. (1962). Diurnal variability in time estimation. Perceptual and Motor Skills, 15, 451-454.

Tune, G. S. (1968). Sleep and wakefulness in normal human adults. British Medical Journal, 2, 269-271.

- (1969a). The influence of age and temperament on the adult human sleep-wakefulness pattern. British Journal of Psychology, 60, 431-441.

(1969b). Sleep and wakefulness in a group of shift workers. British Journal of Industrial Medicine, 26, 54-58.

Voigt, E. D., Engel, P., and Klein, H. (1968). Über den Tagesgang der körperlichen Leistungsfähigkeit. Internationale Zeitschrift für angewandte Physiologie einschliesslich Arbeitsphysiologie, 25, 1-12.

Walker, J. (1966). Frequent alternation of shifts on continuous work. Occupational Psychology, 40, 215-225.

Wedderburn, A. (1972). General discussion: future research needs. In Aspects of Human Efficiency: Diurnal Rhythm and Loss of Sleep, edited by W. P. Colquhoun, p. 335. English Universities Press, London.

Wild, H. W., and Theis, H. (1967). Der Einfluss des Schichtbeginns auf die Unfallhäufigkeit. Glückauf, 103, 833-838.

Wilkinson, R. (1971). Hours of work and the twenty-fourhour cycle of rest and activity. In Psychology at Work, edited by P. B. Warr, pp. 31-54. Penguin Books, Harmondsworth, Middlesex.

- and Edwards, R. S. (1968). Stable hours and varied work as aids to efficiency. Psychonomic Science, 13, 205-206.

Received for publication November 20, 1972.

Accepted for publication March 2, 1973. 